jaundice, dysphagia, diarrhœa and constipation, and so on; thus in this limited sense the book is an index of differential diagnosis.

The descriptions are good and an effort has been made to incorporate clinical facts which are hard to find in text books of medicine but which are of much use at the bedside.

This arrangement makes the book rather scrappy, but justifies its adoption by adding considerably to its value.

The small compass of the book has made the question one rather of what to put in than what to leave out, and generally speaking good judgment has been shown, but occasionally personal interests have overborne the necessities of the case, for instance virilism gets a page and a half and disseminated sclerosis half a page only. A little space could have been saved by better co-ordination; disordered action of the heart is described twice on separate pages.

A few points might have been clearer. The fibrosis of the lung following measles and whooping cough seldom has tuberculosis superimposed, and in the pneumokonioses tuberculosis develops far more frequently where silica is deposited in the lung. The causes of spontaneous pneumothorax are badly stated, no mention is made of the variety which occurs in the apparently healthy, a very important diagnostic point. Endothelioma of the pleura should have a line especially as it is mentioned that 5 per cent. of intra-cranial neoplasms are secondary to foci which are symptomatically insignificant.

On the whole printers' errors are few, " subscapular" appears instead of " subcapsular" on page 87, and on page 115 it says that "The inner two lumbricals are supplied by the median nerve," although the nerve supply is correctly stated two lines above and its implication correctly deduced at the foot of the page.

Certain parts of the book are excellent, especially as might be expected, the section on endocrine glands.

The clinical importance of the appearance of the tongue in differentiating pernicious anæmia and carcinoma of the stomach, the mistake of labelling a chronic appendix in a young man "duodenitis," the reminder that large doses of ephedrine may produce temporary anuria, are examples of the variety of information which the book holds.

On the whole Dr. Simpson has put into this book a great deal of practical bedside knowledge, he has drawn on his experience in condensing for the benefit of the busy practitioner the more important points which he himself considers in making his diagnosis, and in the section on Endocrinology, has put down a series of observations and facts which may turn this subject from a trackless desert into a country full of promise for many a busy doctor. The print is clear and the book well set out and easy to read.

Dr. Levy Simpson has accomplished with a measure of dignity and courage the Herculean task he set himself in compressing medical diagnosis into a volume of this size without sacrificing essential detail.

\section{OPERATIVE SURGERY.}

By Alexander Miles and $D$. $P$. D. WILKIE. Second Edition. Oxford University Press. London. 1936. Price 21/-

In the second edition of this well-known book on Operative Surgery the authors have completely revised the text and have rearranged a number of the subjects in order to facilitate reference. The number of illustrations has been increased.

It is impossible to cover the whole subject of operative surgery in a book composed of 619 pages and the authors have wisely not attempted to do so. They have provided for the needs of undergraduates in the classes of operative surgery and for the recently qualified house-surgeon. The candidate for the higher surgical qualifications will also find the book a valuable basis for his work of preparation.

The operations described are those methods favoured by the authors and alternative operations are not described in detail owing to lack of space. The book may be taken to represent in a general way the practice of the Edinburgh School.

The work is recommended to the junior man who wishes to acquire a sound knowledge of surgery. 